\title{
التوسّع في المعنى في اللغة العربية: دراسة تطبيقية لنماذج من آي القرآن الكريم
}

\section{Comprehensiveness of Meaning in Arabic Language: An Empirical Study of the Models from the Verses of Holy Qur'an}

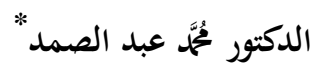

$$
\begin{aligned}
& \text { الملخص: ظاهرة التوسّع في المعنى من أهم ظواهر اللغة العربية ومن أبرز خصائصها التي تميّها من غيرها من }
\end{aligned}
$$

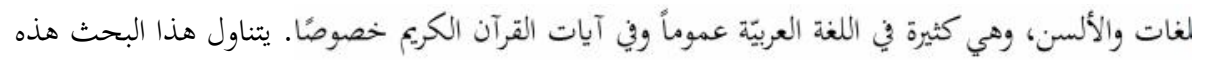

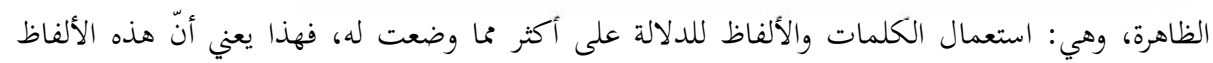

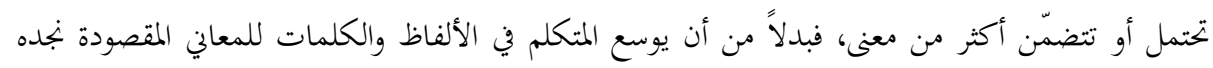

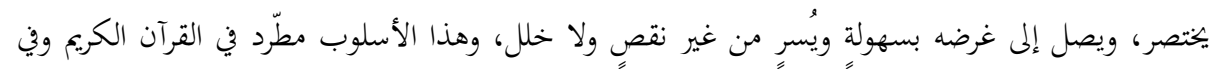

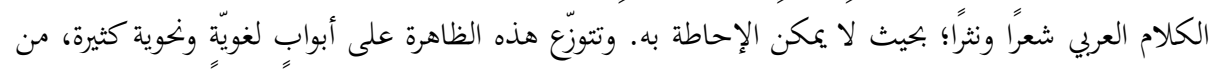

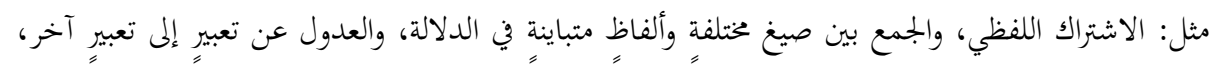

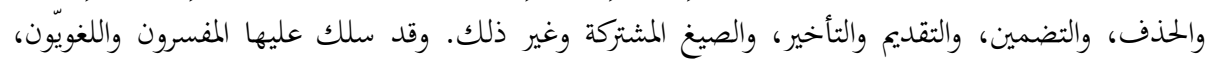

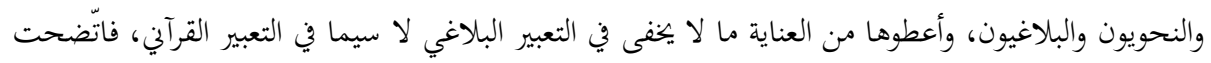

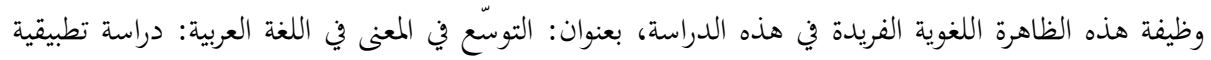

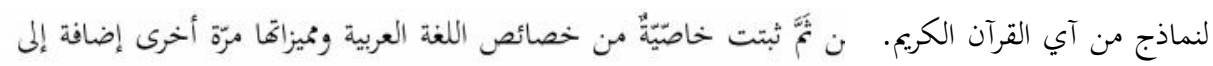

$$
\begin{aligned}
& \text { الدراسات السابقة. } \\
& \text { الكلمات المفتاحية: التوسّع؛ الاشتراك اللفظي؛ الحذف؛ التضمين؛ الصيغ المشتركة. }
\end{aligned}
$$

\begin{abstract}
The comprehensiveness of the meaning is the most important phenomenon of the Arabic language and the most important characteristics that distinguishes the Arabic language from other languages. It is widely used in Arabic language in general, and in the verses of the Qur'an in particular. This article deals with this phenomenon, namely: the use of words to denote more than the original meaning, it means that these words bear or contain more than one meaning, instead, the speaker can expand the meanings of the words by using less words and he can achieve his purpose easily and
\end{abstract}

* Dr Mohammad Abdus Samad, Associate Professor, International Islamic University Chittagong (IIUC), E-mail: samadbinkha@gmail.com 
conveniently without any lacking and defect. This method constantly used in the Holy Qur'an and in the Arabic poetry and prose.

This phenomenon is related to the different linguistic and grammatical aspects, such as: similarity of words, the combination of different forms of words which are different in significance, and refrain from expressions, deletions, inclusion and providing before and after behind, and common forms and so on.

The interpreters, linguists, grammatists and rhetorician followed this, and gave more care in it which is not hidden in the rhetorical expression, especially in the Qur'anic expressions. So, the function of this unique characteristic of the language becomes clear in this study.

Keywords: Comprehensive, Similarity of words, Deletions, Inclusion, Common forms.

$$
\begin{aligned}
& \text { تأتي كلمة التوسّع من مادّة ( وسع )، يعني : الواو والسين والعين، على خلاف معنى الضيق والعسر. يقال: وَسِعَ الشيء، }
\end{aligned}
$$

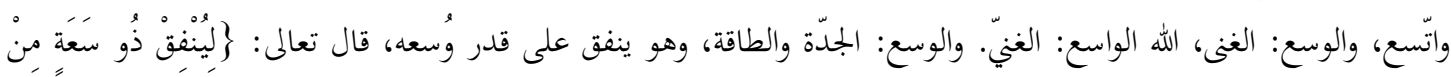

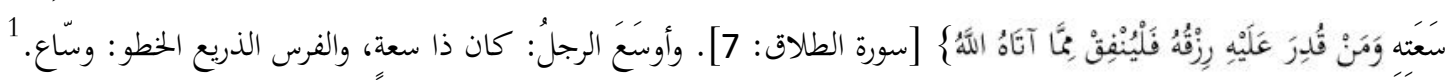

$$
\begin{aligned}
& \text { ومن معانيه اللغوية أيضاً: استعمال اللفظ للدلالة على أكثر مّّا وضع له، أو هو أن يؤتى في آخر الكلام بشيء من مفسّر } \\
& \text { بمعطوف ومعطوف عليه } \\
& \text { وإذا نظرنا في اللغة العربية نجد فيها كثيراً من العبارات والاستعمالات الموجزة التي تتمل أو تتضمن أكثر من معنى، وكلٌّ من } \\
& \text { المعاني مقصود ومطلوب، فإنّ المتكلم بدلاً من أن يوسّع في الألفاظ لأجل المعاني المتعددة نجده يختصره ويصل إلى المعاني المطلوبة }
\end{aligned}
$$

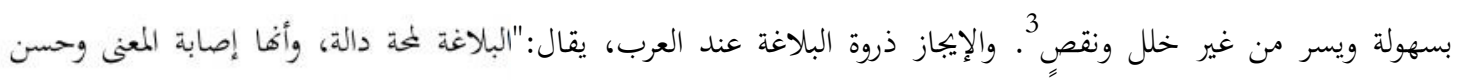

$$
\begin{aligned}
& \text { الإيجاز، وهي كذلك إجاعة (إيجاز) اللفظ وإشباع المعنى" ل4 ولئ. }
\end{aligned}
$$

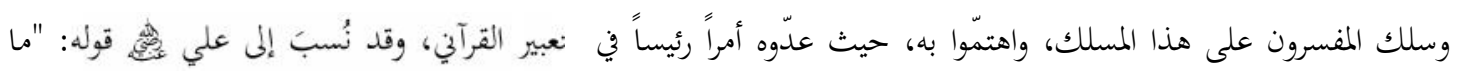

$$
\begin{aligned}
& \text { رأيت بليغاً قط إلاّ وله في القول إيجازٌ وفي المعاني إطالة"5. وكلامه هذا يدلّ على أنّ البلاغة في تقليل الألفاظ وتكثير المعنى. } \\
& \text { وقد تناول ابن جنّي هذا الموضوع في كتابه الحخصائص تحت (بابُّ في اللفظ يرد محتملاً لأمرين أحدها أقوى من صاحبه، أيجازان } \\
& \text { جميعاً فيه أم يقتصر على الأقوى منهما دون صاحبه؟)، فقال: "اعلم أنّ المذهب في هذا ونوه أن يُعتقَدَ الأقوى منهما مذهباً ولا } \\
& \text { يمتنع مع ذلك أن يكون الآخر مراداً وقولاً، من ذلك قوله: }
\end{aligned}
$$

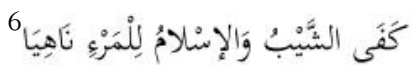




$$
\text { التوسّع في المعنى في اللغة العربية: دراسة تطبيقية لنماذج من آي القرآن الكري / الدكتور مُحَّم عبد الصمد }
$$

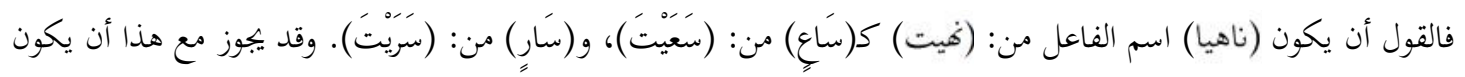

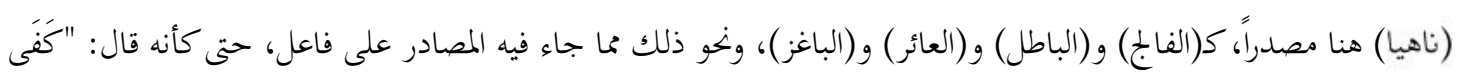

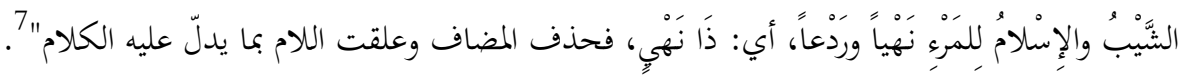

وقد ترد في اللغة العربية ألفاظ، تظهر للقارئ على صورة، وتحتمل أن تكون على صورة أخرى غير ما تظهر، كما في قول الله

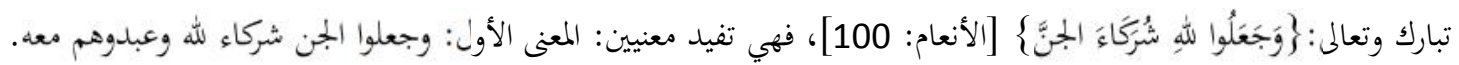

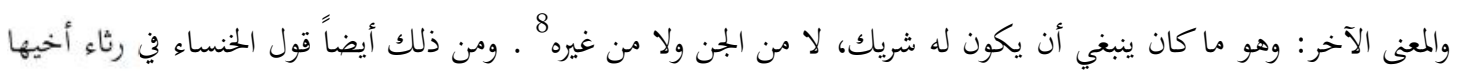
معاوية:

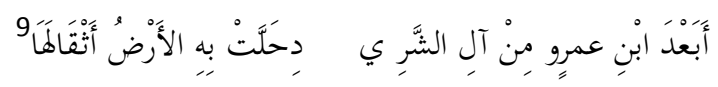

فكلمة (حلّت) في البيت إمّا من (الحلية) أي: زيَّتت به موتاها، أو من: (الحَل)، كأنه لما مات انحل به عقد الأمور، كما قال ابن الأعرابي 10.

فاتضضح مما سبق من بعض الأمثلة أن في اللغة العربية ميزة قلّما نجدها في غيرها من اللغات، وهي التعبير باللفظ القليل عن المعنى الكثير، فيتوسّع في المعنى دون أن يتوسّع في الكلمة، ومن ذلك يصل المتكلم إلى مراده من أيسر طرقٍ وبأقل تعبٍ. وأتناول في هذه الدراسة بعض الظواهر اللغوية التي تُوسّع فيها المعنى دون اللفظ، وأقتصرها على عرض بعض نماذج من الآيات القرآنية المختارة. وهذه الظواهر كثيرة في اللغة العربية، ومن أهمها ما يلي:

\section{أولاً: الاشتراك اللفظي}

وهو من أهمَ الظواهر في اللغة العربية التي يتوسّع فيها معاضٍ كثيرة بألفاظٍ قليلة. وله شواهد كثيرة في اللغة العربية. وبه يتوصّل المتكلمّ إلى معانٍ كثيرةٍ خلافاً للألفاظ وتغطية المدلولات الاجتماعية التي تتجدّد في المجتمع حتى تفي بمطالب الحياة والأحياء ل. 11. والاشتراك اللفظي هو: ما اتفقت صورته واختلف معناه، كما قال سيبويه: "وَجَدْتُ عليه، من: الْمَجِدة، ووَجَدْت: إذا أردت

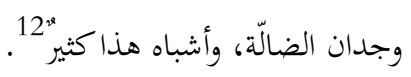

وكذلك كلمة (العين) نعني: النقد من الدراهم والدنانير، وعين السحاب، وعين الإنسان، وعين الماء، والجاسوس، وغيرها 13. 
وكذلك (الأرض) المعروفة: وكلّ ما سَفَلَ فهو أرضٌ، و(الأرض): أسفل قوائم الدابّة، و(الأرض): النَفْضَةُ والرَّعَدَة، و(الأرض):

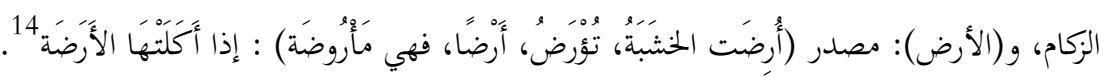

ولاشك في أنّ التعبير يتّسع من طريق الاشتراك اللفظي؛ لأنّه يرد للفظ المشترك أكثرُ من معنى واحدٍ، وهو يصلح أن يكون من ــ التورية والتجنيس عند أصحاب البديع، وقد ذكر السيوطي أنّ سلامة الأنباري أنشد ثلاثة أبياتٍ في شرح المقامات على لى قافية واحدة يستوي لفظها ويختلف معناها، وهذه الأبيات هي:

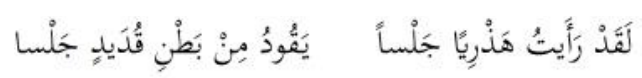

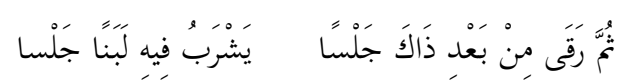

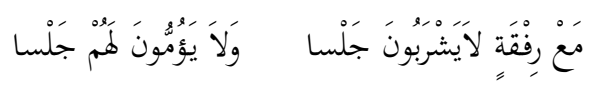

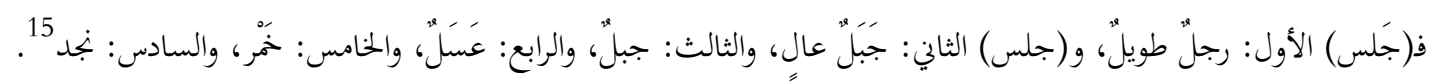

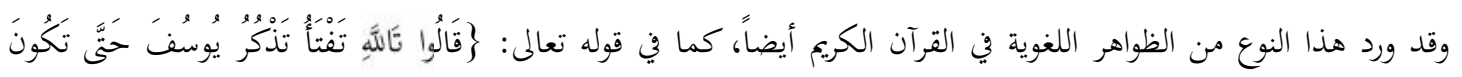

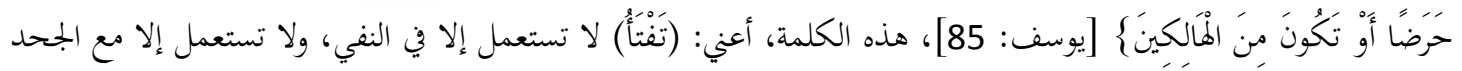

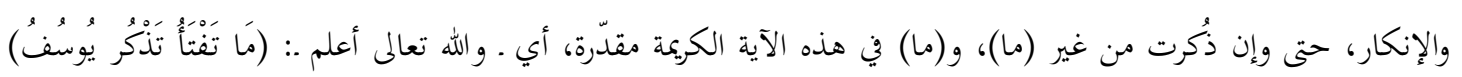

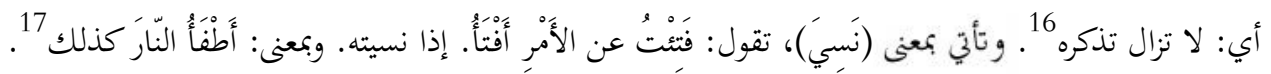
وقد تضمن فعل (تَفتأ) في الآية الكريمة هذه المعاني كلها، بمعنى أنّ يعقوب عليه السلام لا يمكن أن ينسى ذكر يوسف ولا يكفّ

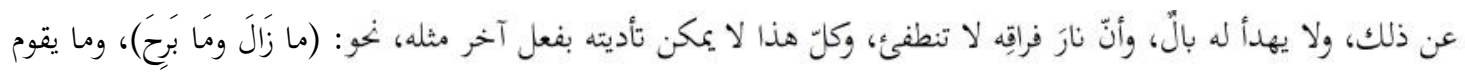
مقامهما

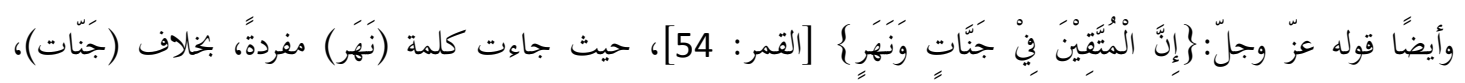
جاءت جمعاً، وهو أمر انفردت به هذه الآية من نظيرتحا في بقيّة الآيات القرآنية؛ لأنّ كلمة (نَهَرَ) لمُ ترد فيها إلاّ جمعًا مطابقاً

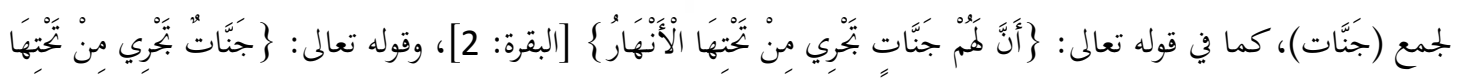

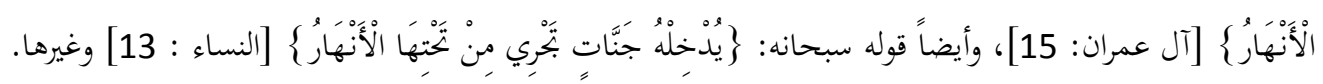
مما يرجح أنه عند إرادة تضمين كلمة (نَهَر) أكثر من معنى وفائدة جيء بها مفردة، ولا تتأتى هذه المعاني وهي جمعُ، إضافةً إلى ذلك أنَ فواصل الآيات تقتضي (النَّهَ)، وليس (الأفمار)؛ لأنّ آيات السورة جاءت كلها على هذه الفاصلة، أو على هذا الوزن. 


$$
\text { التوسّع في المعنى في اللغة العربية: دراسة تطبيقية لنماذج من آي القرآن الكري / الدكتور مُحَّم عبد الصمد }
$$

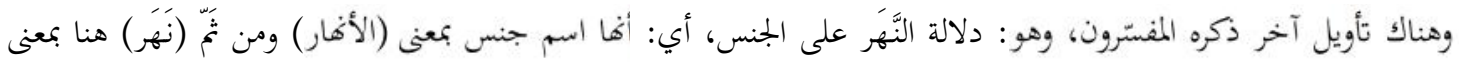
الجمع ". وبجيء الكلمة مفردة والمراد بها جمع كثير" في كلام العرب، وفي القرآن الكريع ل. ومن معاني (النَّهَ)): السعة، نحو قول قيس بن الخطيم في وصف طعنة:

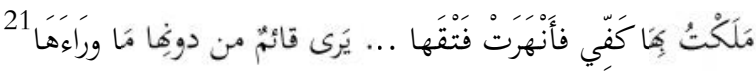

$$
\text { يقصد ب(أنهُرَت فتقها): وسعت فتقها } 22 .
$$

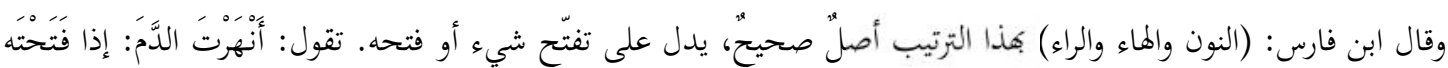

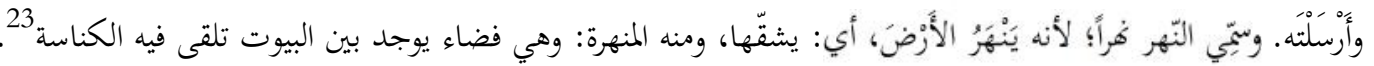
ويبدو أنّ السعة المستنبطة من كلمة (نَهَرَ) في الآية الكريمة عامة، تشمل سعة المعيشة والأرزاق والمنازل. كما وردت بمعنى الضياء؛ لأن الجنّة ليس فيها ليلّ، إنما هو نور يتلألأُ24. ويتبين مُّا سبق أنّ كلمة (نَهَر) تعددت معانيها وكلها مطلوب، ف(المتّقُونَ) يتنعمون في المأكل والمشرب والملبس والمسكن، وأيضًا

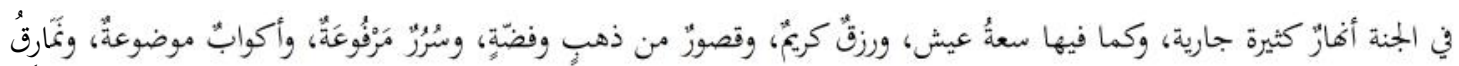

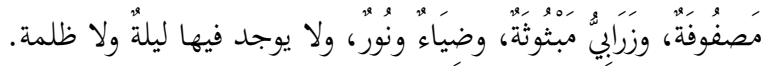

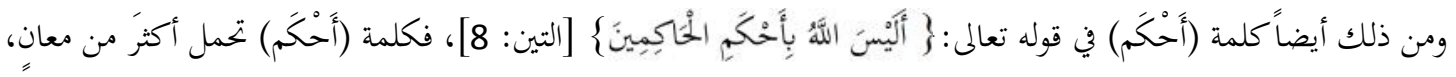
فقد تكون من الحُكم، أي القضاء، وأقضى الحكماء، كما أنه أحكم القضاة وأحكم الحكماء، فيكون قد اجتمع أربعة معان في كلمة واحدة كلها صالحة مقصودة 25.

\section{ثانيًا: الصيغ المثتركة}

تأتي صيغة بمعنى صيغة أخرى كثيرًا في لسان العرب، كما يأتي اشتراك معان متعددة في صيغة واحدة. فوزن (فَعيل) مثلاً صيغة تشترك مع الأسماء والمصادر واسم الفاعل واسم المفعول وصيغ المبالغة والصفة المشبهة، والمصدر الميمي واسمي الزمان والمكان.26. وكذلك الأمر مع اسم المفعول من الثلاثي المزيد نهو: (مُفَّلَ ومُفاعَل ومفعَل) يشترك مع المصدر الميمي واسمي الزمان والمكان، وفي الحقيقة أنّ التفريق بين هذه الصيغ صعبّ إلا بالرجوع إلى السياق، فككَها تتفق في صياغتها من غير الثلاثي الجرد بإبدال حرف المضارعة ميماً مضمومة وفتح ما قبل الآخر. 
فكلمة (مختار) مثلاً مشتركة بين عدّة مشتقات: اسم الفاعل واسم المغعول والمصدر الميمي واسمي الزمان والمكان. فعندما نقول (هذا مختارُنا) يكون له عدّة معان محتملة، فهي اسم فاعل إذا قصدنا: هذا هو الذي إِحَتَرَكَ، وهي اسم مفعول إذا قصدنا: هذا

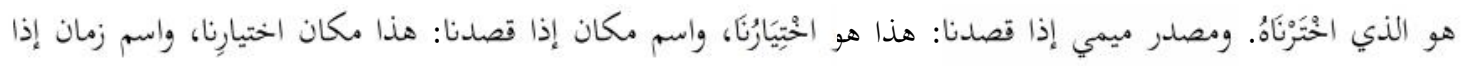
قصدنا: هذا زمان اختيارِنا. ومنه يتبين أنه يمكن للمتكلم أن يضمّنْ أكثر من معنى في تعبير واحد، وهو باب من أبواب التوسّع في المعنى 27.

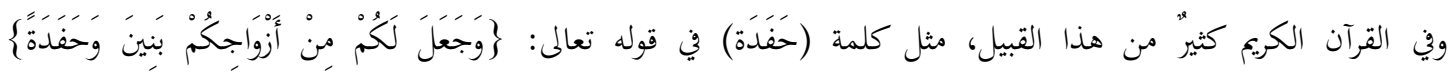
[النحل:72]، فهي تحتمل أكثر من معنى، وكل المعاني هنا مطلوب ومراد، وهذه المعاني هي: الخدم والأعوان، وقيل: أبناء المرأة من غير زوجها. وقيل: الأصهار، وقيل: ولد الولد. ونجد هذه الكلمة في المعاجم اللغوية تدلّ على الخفة في العمل والسرعة في المشي. يقول ابن فارس: "الحاء والفاء والدال أصلّ يدل على الحفة في العمل والتجمع. فالحَفَّة: الأعوان لأفم يجتمع فيهم التجمع والتخفف، واحدهم حافد. والسرعة إلى الطاعة

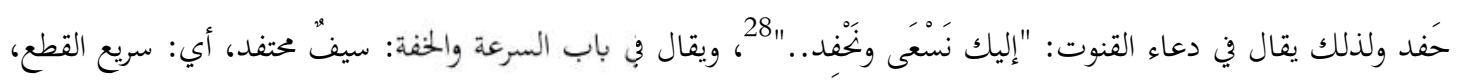
والحفدان: تدارك السير"29. وقد علّق عليه أبو جعفر يُحَّمَ بن جرير الطبري بعد ذكر معاني (حَفَدَة) المتعددة قائلاً: "ولم يكن الله تعالى دلّ بظاهر تنزيله، ولا على لسان رسوله صلّى الله عليه وسلّم، ولا بحجة عقلٍ، على أنه عنى بذلك نوعًا من الحفدة، دون نوٍِ منهم، وكان قد أنعم

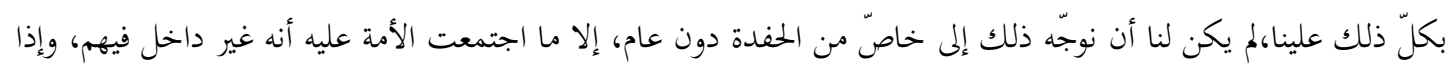
كان ذلك كذلك فلكلّ الأقوال التي ذكرنا عمّن ذكرنا وجه في الصحة، ومَّْج في التأويل" "30.

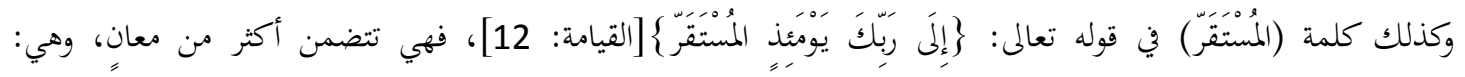
الاستقرار، ومن ثََّّ تكون مصدراً، ومكان الاستقرار، وتكون حينئذ اسم مكان، ويمكن أن تكون بمعنى زمان الاستقرار، فتكون اسم زمان. وقال الزخشري في شرح الكلمة: "إلى ربّك خاصة (يومئذ) مستقر العباد. أي استقرارهم: بمعنى أفّم لا يقدرون أن

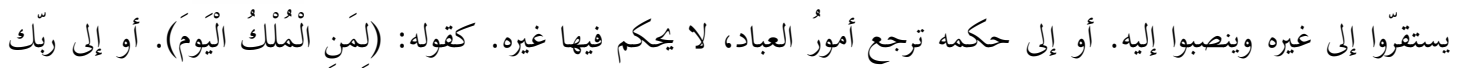
مستقرهم: أي موضع قرارهم من جنة أو نار "31 إن. وذكر مثله أبو حيان الأندلسي عند تفسير هذه الآية الكريمة، فقال: (المستقرّ): الاستقرار، أو موضع استقرار من جنة أو نار 32. 
التوسّع في المعنى في اللغة العربية: دراسة تطبيقية لنماذج من آي القرآن الكري / الدكتور مُحّهُ عبد الصمد

كما يمكن أن تدل على زمان الاستقرار وهو وقت الفصل بين المخلوقات ودفتهم إلى مستقرهم، فمدّة مكوثهم في ذلك اليوم مرتبط بمشيئة الله تعالى. وهكذا فإنّ لمذه الكلمة ثلاثة معان محتملة يمكن استباطها من الآية، ولو جاءت كلمة (الاستقرار)

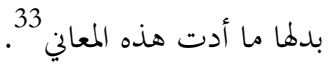

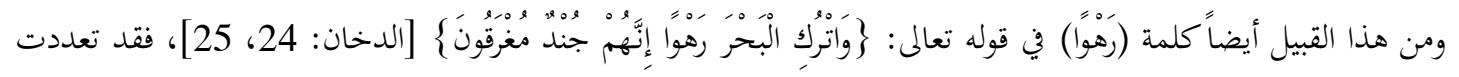

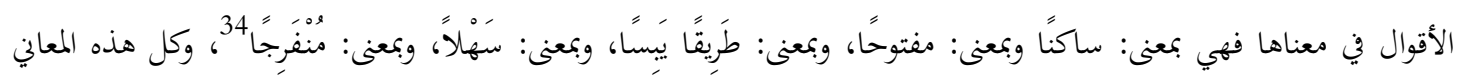
مقصود، و الله تعالى أعلم.

\section{ثالئًا: الجمع بين ألفاظ مختلفة وصيغ متباينة في الدلالة}

وهذه الظاهرة كثيرة في القرآن الكريم، فعندما نتلو آياتٍ من كتاب الله تعالى ونتدبرها نجد هذا النوع من الظواهر اللغوية، وهي

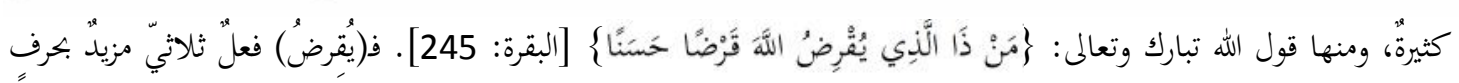

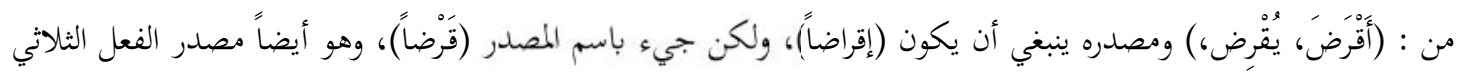

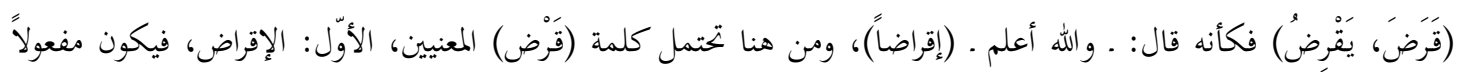

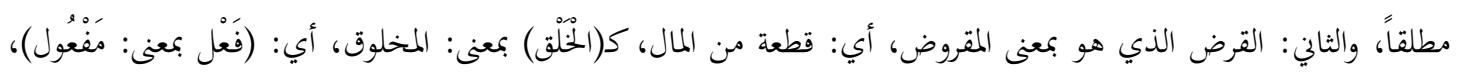
فيكون مفعولاً به. وكلا المعنيين مقصود، الإقراض الحسن والمال الحسن ووصفه بالحسن إما لكونه طيب النية خالصاً لله تعالى،

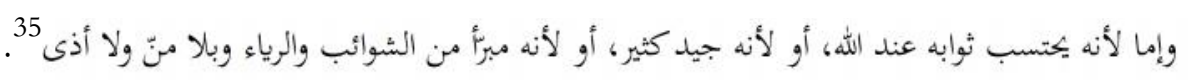

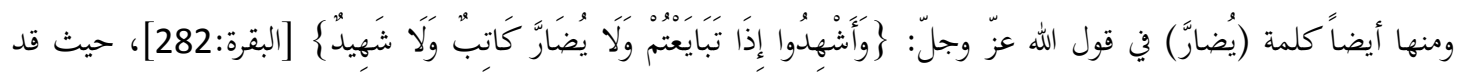

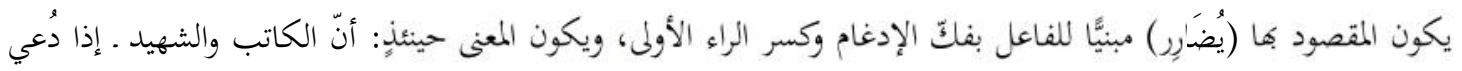
أحدها وهو مشغول 36. قد نَهَيا أنْ يضارًَا أحداً بأن يزيد الكاتب في الكتابة أو يحرِفِ، وبأن يكتم الشاهد الشهادة أو يغيرها أو يمتنع من أدائها.... وقال ابن عباس وبجاهد وعطاء: بأن يقولا علينا شغل ولنا حاجة" ويحتمل أن يكون (يُضَرَرَ) مبنيًا للمفعول، بفكّ الإدغام وفتح الراء الأولى، وعلى هذا يكون المعنى: نَهَى أن يضارَّما ـ الكاتب

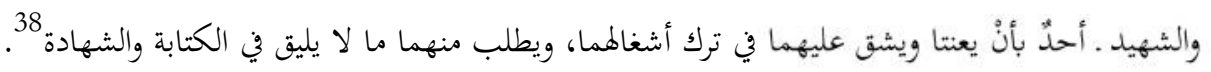
وخلاصة الكلام أنّ المعنيين مرادان في (يُضارّ)؛؛ لأنّ على الكاتب والشهيد ألا يَضرّا أحدًا، ولا أحدٌ يوقع عليهما الضرر، ولهذه الحكمة ـ والله تعالى أعلم ـ ربّما جاءت (يُضارّ) بالإدغام، إذلو لو أريد تحديد أحد المعنيين لقيل: لا يُضارِ أو لا يُضارَر. 


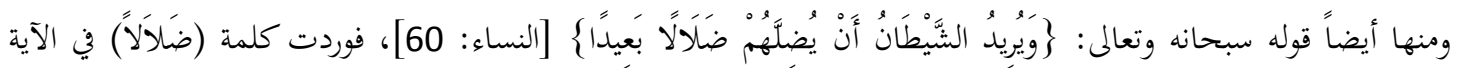

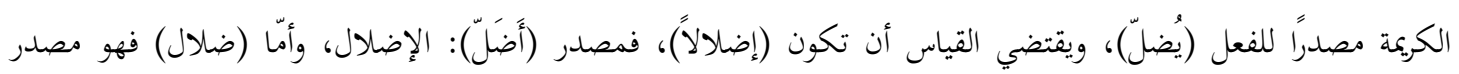

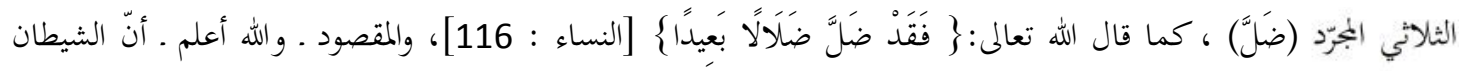

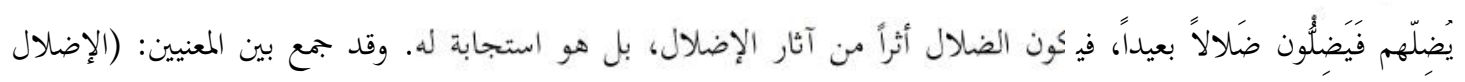

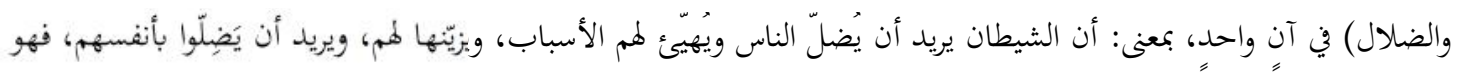

$$
\begin{aligned}
& \text { يفتح الباب ويبدأ المرحلة وهم يتموها } 39 . \\
& \text { رابعاً: العدول عن تعبيرٍ إلى تعبيرٍ آخر }
\end{aligned}
$$

ومن ميزات اللغة العربية أن يعدل عن تعبير إلى تعبيرٍ آخر لغرضٍ معيٍّ يقتضيه المعنى أو المقام، وهو كثيرِ في القرآن الكريم، ومن

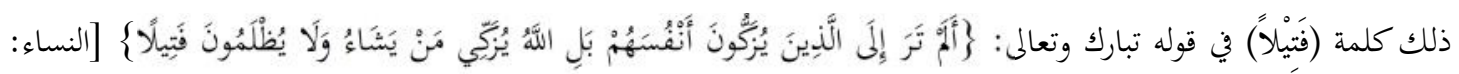

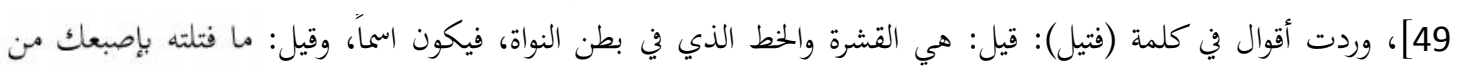

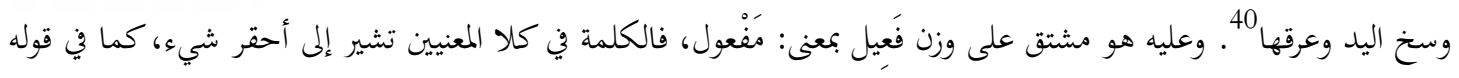

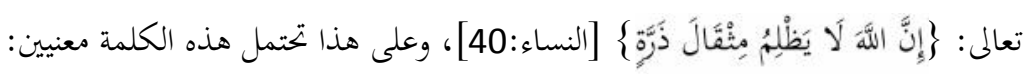
الأول: أن يقصد بالفتيل (الظلم) أي: لا يُظلمون ظلماً قدر فتيل، وتكون الكلمة مفعولاً مطلقاً نائباً عن المصدر المخذوف فهو

والثاني: : يقصد بالفتيل معناه الحقيقي، فيكون مفعولاً ثانياً بتضمين (يُظلمون) معنى (يتقص) أو (ينقص) وهو متعد إلى مفعولين

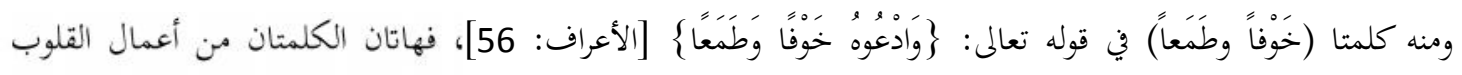

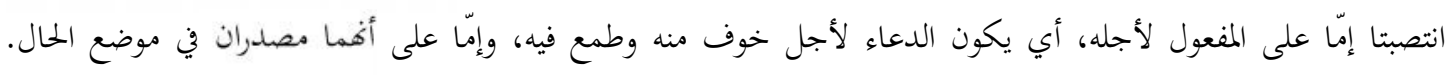

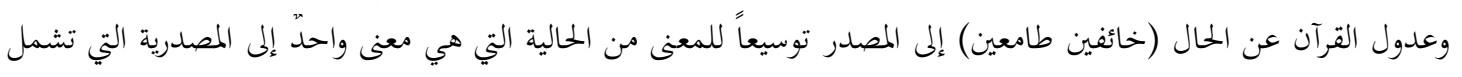

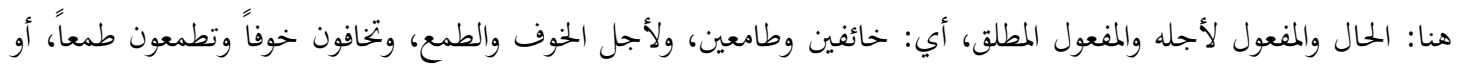

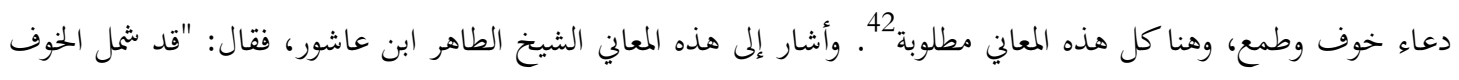

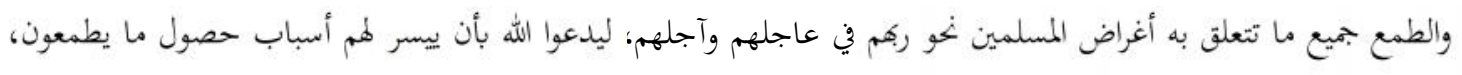
وأن يجنبهم أسباب حصول ما يخافون. وهذا يقتضي توجه همتهم إلى اجتناب المنهيات لأجل خوفهم من العقاب وإلى امثتال المأمورات لأجل الطمع في الثواب" 43 


$$
\text { التوسّع في المعنى في اللغة العربية: دراسة تطبيقية لنماذج من آي القرآن الكري / الدكتور مُحَّم عبد الصمد }
$$

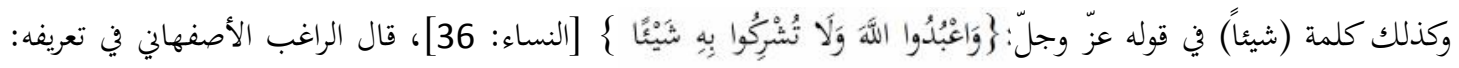
"إنّ الشيء هو الذي يصحّ أن يعلم ويخبر به، كما أنه اسم مشترك المعنى، إذ استُعمل في الله وفي غيره، ويقع على الموجود

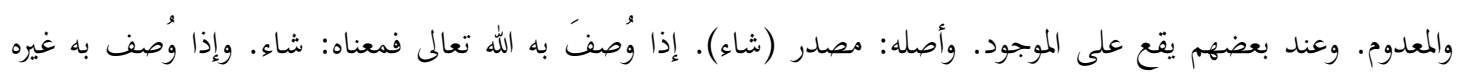

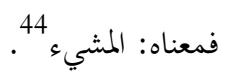

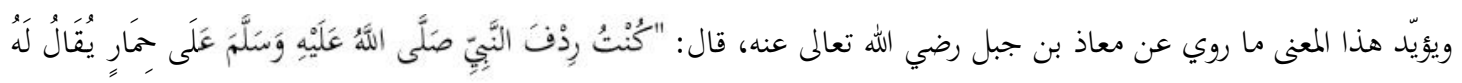

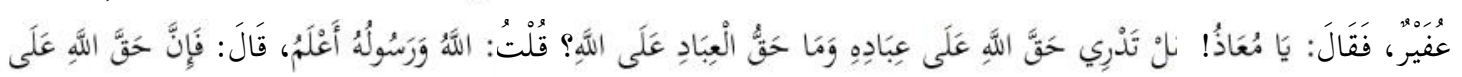

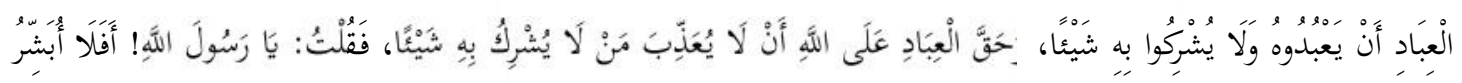

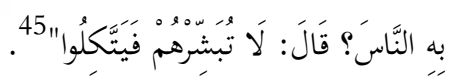
وعليه يمكن أن تكون كلمة (شيئاً) في الآية كناية عن الشرك، أي: لا تشركوا به أيّ شيء من الشرك ولو كان قليلاً، فتكون حينئذ مفعولاً مطلقاً أو نائباً عنه، ويحتمل أن يقصد (بالشيء) ما يُعبدَ من دون الله، فتكون عندئذ مفعولاً به. وبناء على ما سبق يمكن القول بأن كلمة (شيئا) في الآية جمعت بين معنيين في آنٍ واحدٍ؛ النهي عن إشراك أيّ شيء من الشرك

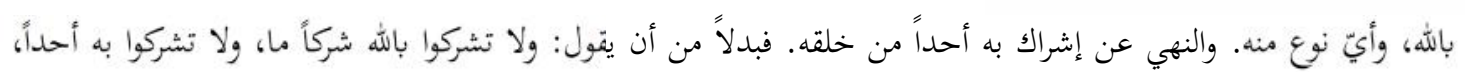
قال: ولا تشركوا به شيئاً.

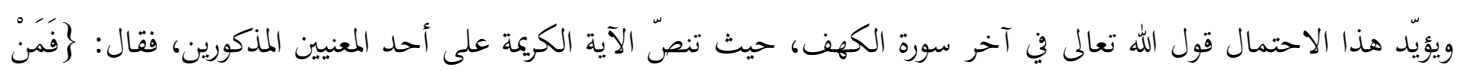

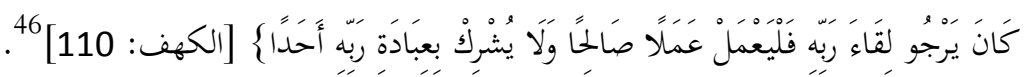

\section{خامساً: الحذف}

إنّ المتكلم قد يحذف بعض عناصر الكلام لأغراضٍ معيّنة، وقد يكون للمحذوف صلة به أو لا يكون، وعلى كلّ فإنّ للحذف

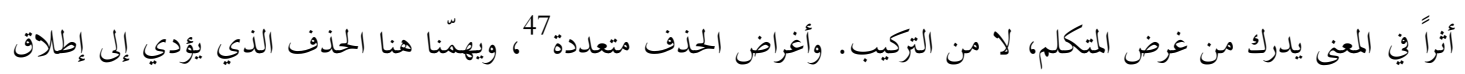
المعنى وتوسيعه، وذلك في التعبيرات التي يحتمل فيها المحذوف عدة معانٍ وتقديرات، فما أمكن تقديره لدى السامع، وأمكن أن يكون معنى مقصودا، يدخل في باب التوسّع في المعنى في اللغة العربية 48.

ومن أمثلة الحذف في القرآن الكريم كثيرُ، ومنها قوله تعالى:

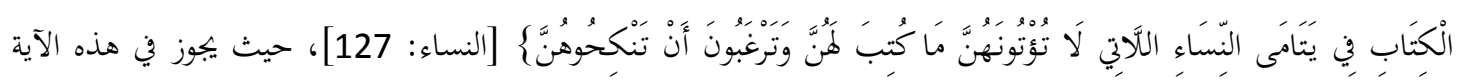


تقدير حرف الجر في (أن تنكحوهنّ) وجهان: (في) و(عن)، فعلى الأول يكون التقدير: وترغبون في أن تنكحوهن لجمالهن

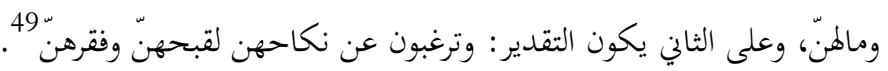

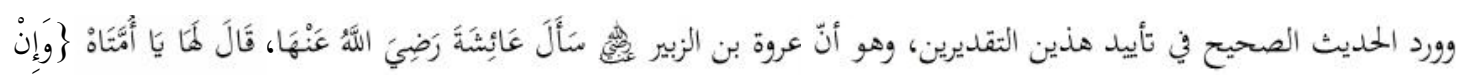

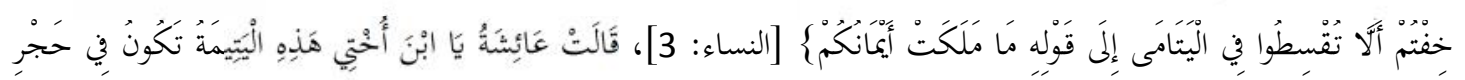

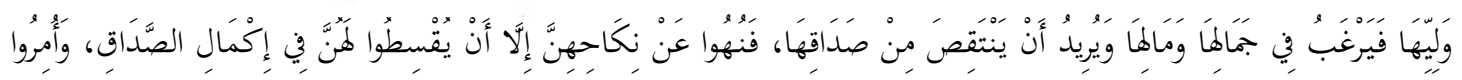

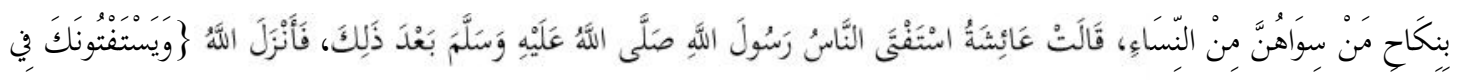

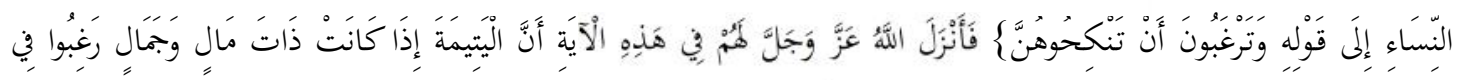

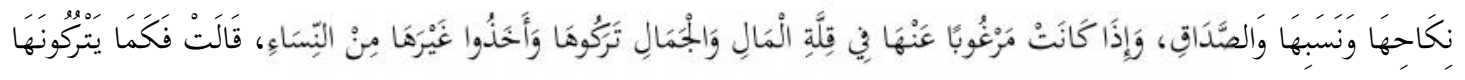

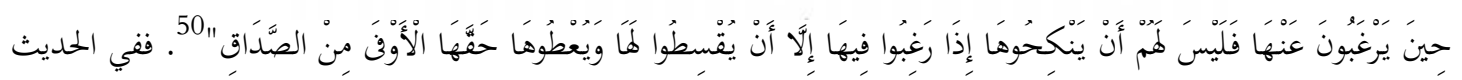

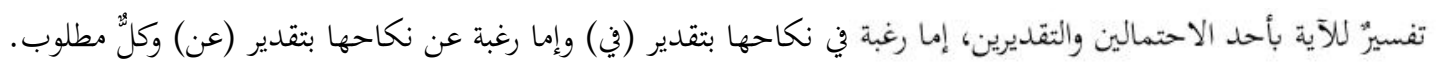

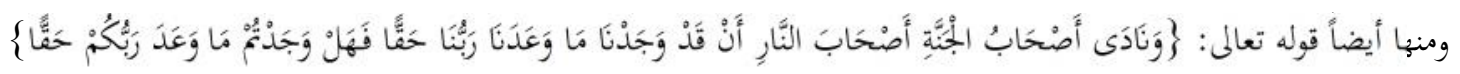

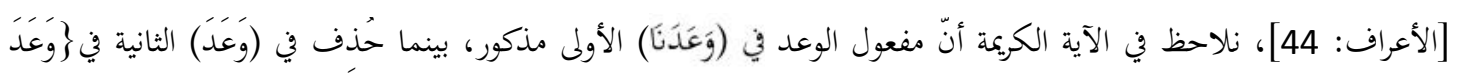

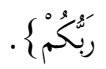

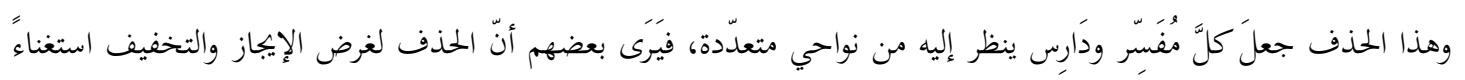

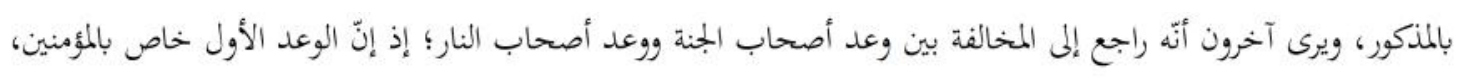
ومن ثم ذكر مفعوله، وأن الوعد الثاني عام مطلق، ويشمل كل ما وعد الله عباده من البعث والحساب والثواب والعقاب وغير وري

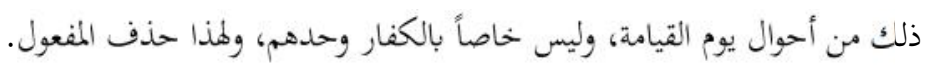
ومنهم من يرى أن الغرض من الحذف إبراز للمفارقة بين ما يُعطاه المؤمنون من بنعمِ وتكريم، وبين ما يُجازى به الكفار من نقمةٍ

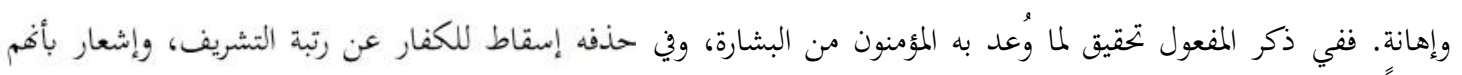

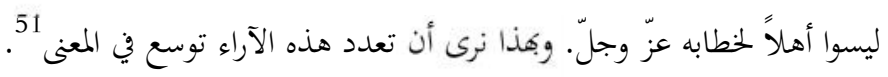

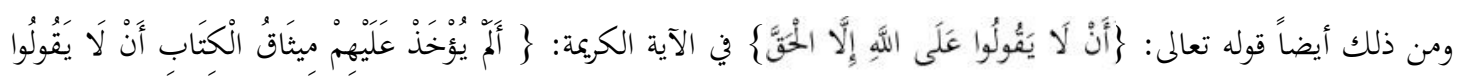

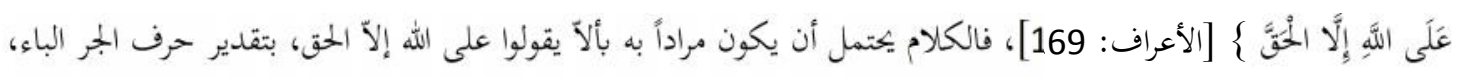
كما يحتمل أن يكون المقدر (في) أي: في ألاّ يقولوا على الله إلا الحق، كما يقال: أخذ بالوثيقة في أمره، وتوثق في أمره، مثله.

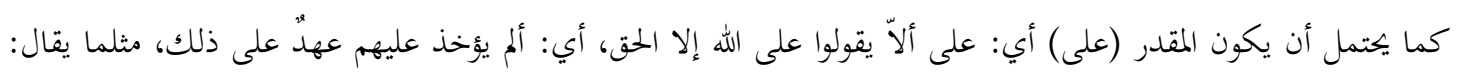




$$
\text { التوسّع في المعنى في اللغة العربية: دراسة تطبيقية لنماذج من آي القرآن الكري / الدكتور مُحَّم عبد الصمد }
$$

تواثقنا على الإسلام، أي: تحالفنا وتعاهدنا. ويحتمل أيضاً أن يكون المقدر اللام، فيكون المعنى: (لئَلَّ يقولوا على الله إلا الحق). ويبدو ـ والله أعلم ـ أنّ هذه المعاني الثلاثة كلها محتملة في الآية، وسبهها حذف حرف الجر، وهو كثير في القرآن الكريع 52. وإلى جانب آخر يحتمل هذا الكلام معاني متعددة، يمكن أن تكون كلها مطلوبة، منها: أن تكون عطف بيان لميثاق الكتاب

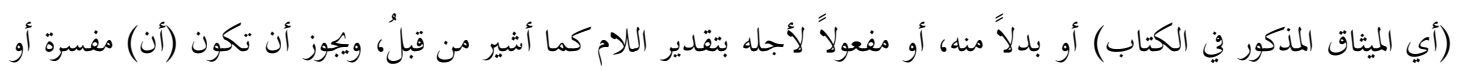
مصدرية، وعندها يكون الميثاق بمعنى القول، ويختمل أنْ تكون (لا) ناهية أو نافية كذلك، ومن ثم كسب هذا التعبير معنى (في) و (على) و(الباء) وعطف البيان والبدلية والمفعول لأجله والتفسير والمصدرية والنهي والنفي، هي عشرة معان محتملة ولو ذكر أي” حرف لتحدد المعنى به 53

\section{سادساً: النضمين}

هو نوع من الاتساع الذي يعد من أساليب العرب المميزة في كلامهم، والتضمين في اللغة: الكفيل. يقال: ضمن الشيء وبه ضمناً وضمانأ: كفل به، وضمنه إياه: كفله. ويطلق أيضاً على: الإيداع. يقال: ضمن الشيء: أودعه إياه كما تودع الوعاء المتاع. وقد تضمنه هو 54 . وقد يأتي التضمين في اللغة العربية لأربعة مقاصد: التضمين العروضي، والأدبي (البلاغي) والبياني والنحوي 55 ويهمنا في هذا الموضوع (التضمين النحوي)، وقد عرّفه كثير من اللغويين والنحويين، وأشاروا إليه 56. ومن ذلك: "أن يؤدي فعل أو ما في معناه

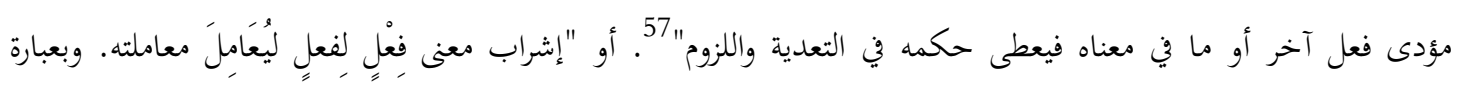
أخرى: هو أن يحمل اللفظ معنى غير الذي يستحقه بغير آلة ظاهرة"58. ومن آثاره إفادة اللغة تيسيراً واتساعاً من أخصر طريق وأوجزه، حيث تؤدي كلمة واحدة مؤدى كلمتين، فيكون في ذلك جمع بين الحقيقة والمجاز؛ لدلالة المذكور على معناه بنفسه وعلى معنى المخذوف بالقرينة 59. ويكون التضمين في الأسماء والأفعال والحروف، إلا أنه في الأفعال أظهر؛ لوجود قرينة لفظية توضحه كما سيأتي، وقد ورد في

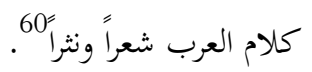

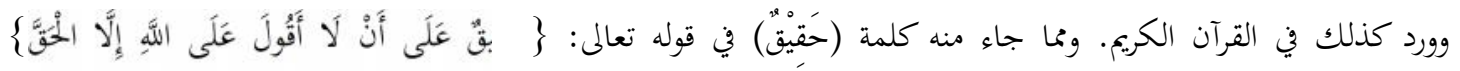

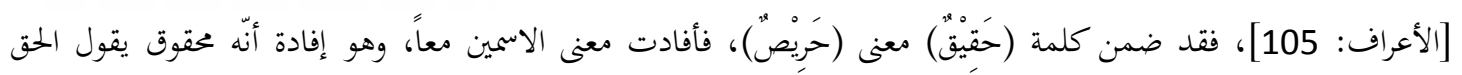
وحريص عليه 61. 


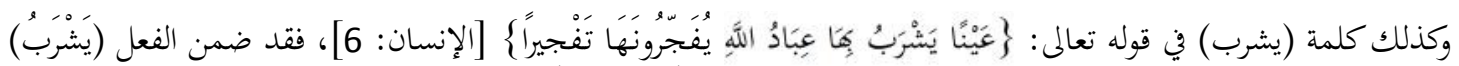

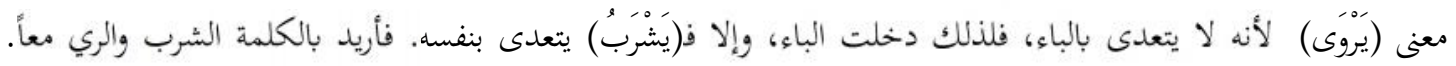
ويكون أيضاً قد جمع بين الحقيقة والمجاز بلفظ واحد، وفي ذلك اختصار في اللفظ وتوسيع في المعنى. لَّ إنّ الثضمين هو إ شراب اللفظ معنى زائداً على أصل معناه، وتبدو فيه أيضاً القيمة البلاغية؛ لأنّ المتكلم لا يأتي به عبثا؛، وإنما

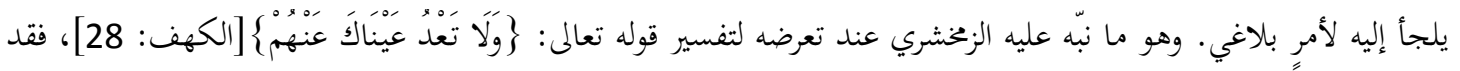

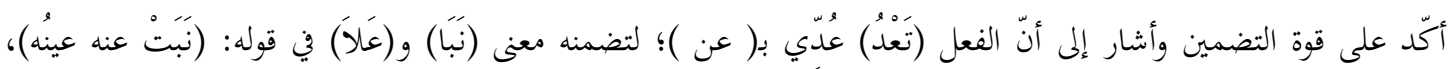

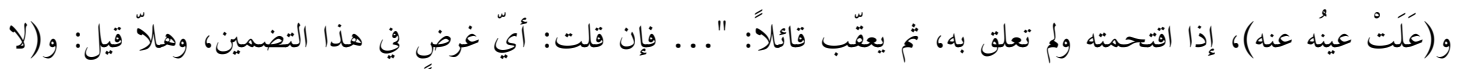
تعدُهم عيناك، أو (لا تَعْلُ عيناك عنهم)؟ قلت: الغرض فيه إعطاء مجموع معنيين، وذلك أقوى من إعطاء معنى فَذّ، ألا ترى فئه كيف رجع المعنى إلى قولك: ولا تقتحمهم عيناك بحاوزتين إلى غيرهم، ونحوه قوله تعالى:

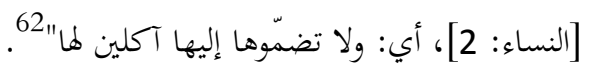

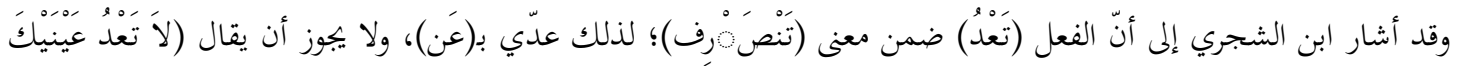

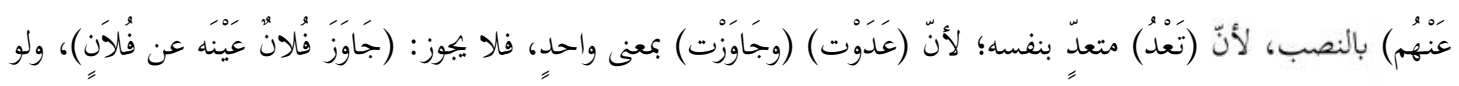
كانت التلاوة بنصب العين لكان اللفظ يتضمنها محمولاً أيضاً على: (لاَ تَصْرِفِ عينَك عنهم)، وإذا كان كذلك، فقراءة رفع

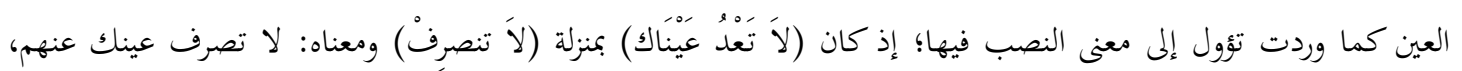

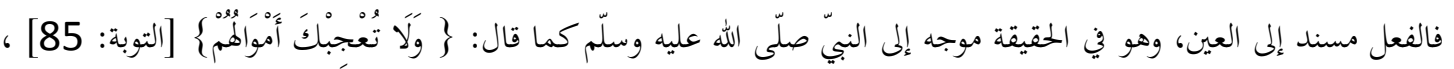

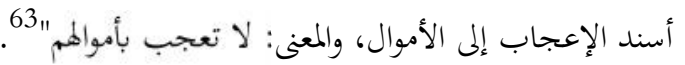
سابعاً: التقديم والتأخير يُعدَ موضوع التقديم والتأخير من الأساليب البلاغية في اللغة العربية، وعلاقته بالتركيب أقلّ؛ لأنّ العرب يستعملون هذا الأسلوب

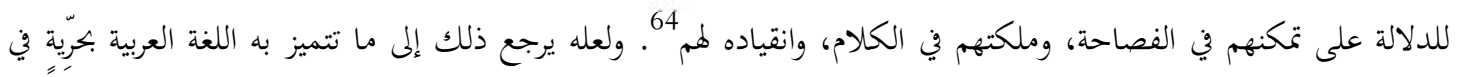
يب مفرداتا؛ لأجل ظاهرة الإعراب، وقد درس النحويون مواقع الكلمات في الجملة بعضها من بعض من حيث المستوى الصائب، وأطلقوا عليها (الرتبة المففظة)، أي: راعوا فيها مراتب الكلام، كمجيء الفاعل قبل المفعول، والمبتدأ قبل الخبر، والمضاف قبل المضاف إليه، والموصوف قبل الصفة وهكذا، بينما أطلقوا اصطلاح (الرتبة غير المحفوظة) على المواقع التي يجوز فيها تقديم بعض أجزاء الجملة على بعض، ويكون للمتكلّم حقّ التصرّف في تغيير مواضع الكلمات داخل السياق وفق قواعد لغوية 


$$
\text { التوسّع في المعنى في اللغة العربية: دراسة تطبيقية لنماذج من آي القرآن الكري / الدكتور مُحّمَ عبد الصمد }
$$

وقد سلك البلاغيون مسلك النحويين، إلاّ أفّم ركزوا على (الرتبة غير المفوظة)؛ لما فيها من خروج عن الأصل لأسباب فنية

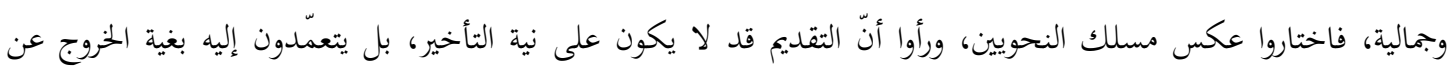
الأصل والعدول عنه؛ لما في ذلك من قيم فنيّة بلاغية، وأنّ الشيء قد ينقل من حكم إلى آخر لغرضٍ يريده المتكلم. ولعلهم استنبطوا من عبارة إمام النحويين سيبويه، حيث قال: "... كأَّمَ إنما يقدّمون الذي بيانه أهم لهم، وهم ببيانه أغنى، وإن

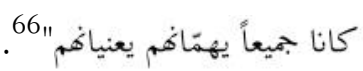

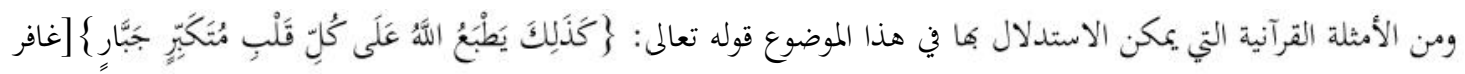
35: لكنّ" القرآن غيّر موضع المتضايفين (كل وقلب) فجعل المضاف مضافاً إليه، والمضاف إليه مضافاً لفائدة لا يؤديها التعبير

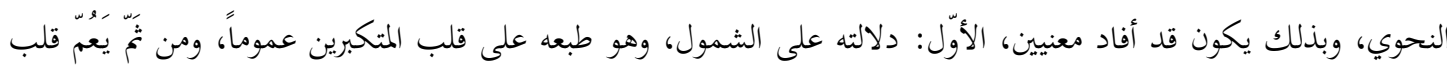
كل متكبر جبار، وقد ورد عن الألوسي قوله: "الظاهر أنّ عموم (كل) منسحب على المتكبر والجبار أيضاً فكأنه اعتبر أولاً إضافة (قلب) إلى ما بعده، ثم اعتبرت إضافته إلى المجموع" والثاني: "دلالته على الشمول أيضاً، لكنه يخص هذه المرة القلب كله لا جزأه، فيكون الطبع مستغرقاً كل قلبه وكل قلوب المتكبرين الجبابرة عموماً لا يدع شيئاً منها. ومن ذلك يكون هذا التعبير قد أفاد المعنيين جميعاً، ولو جاء بالتعبير المفترض لأفاد استغراق الجبابرة ولا يفيد استغراق القلب كله 68.

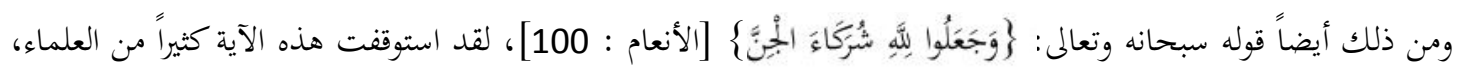
واختلفوا في إعراب كلمة (الجن)، وما ترتب عليها من اختلاف في المعنى وتوسيعه، فمنهم من يعدّها مفعولاً أول، (وشركاء) مفعولاً ثانياً، ومنهم من يعدَها بدلاً من شركاء، ومنهم من يعدّها بالجر 69. ولاشك في أنّ هذا التعدد في الإعراب وفي القراءة، هو تعدد في المعنى وتوسع فيه، وكل راجع إلى التقديم والتأخير. ويبدو لنا أن

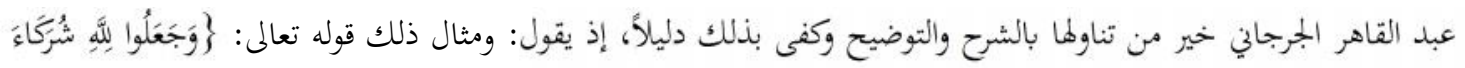
الجْنَُّّ، ليس بخافٍ أنّ في تقديم الشركاء حسناً وروعة ومأخذاً من القلوب، أنت لا بتحد شيئًاً منه إنْ أنت أخرت، فقلت: وجعلوا الججن شركاء لله. وأنك ترى حالك حال من نقل عن الصورة المبهجة والمنظر الرائق والحسن الباهر إلى الشيء الغفل الذي

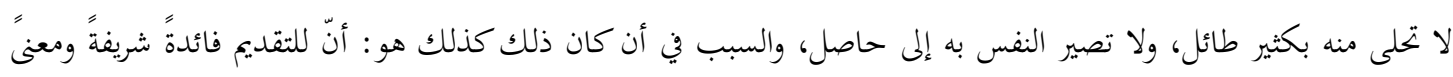
جليالًا لا سبيل إليه مع التأخير. 


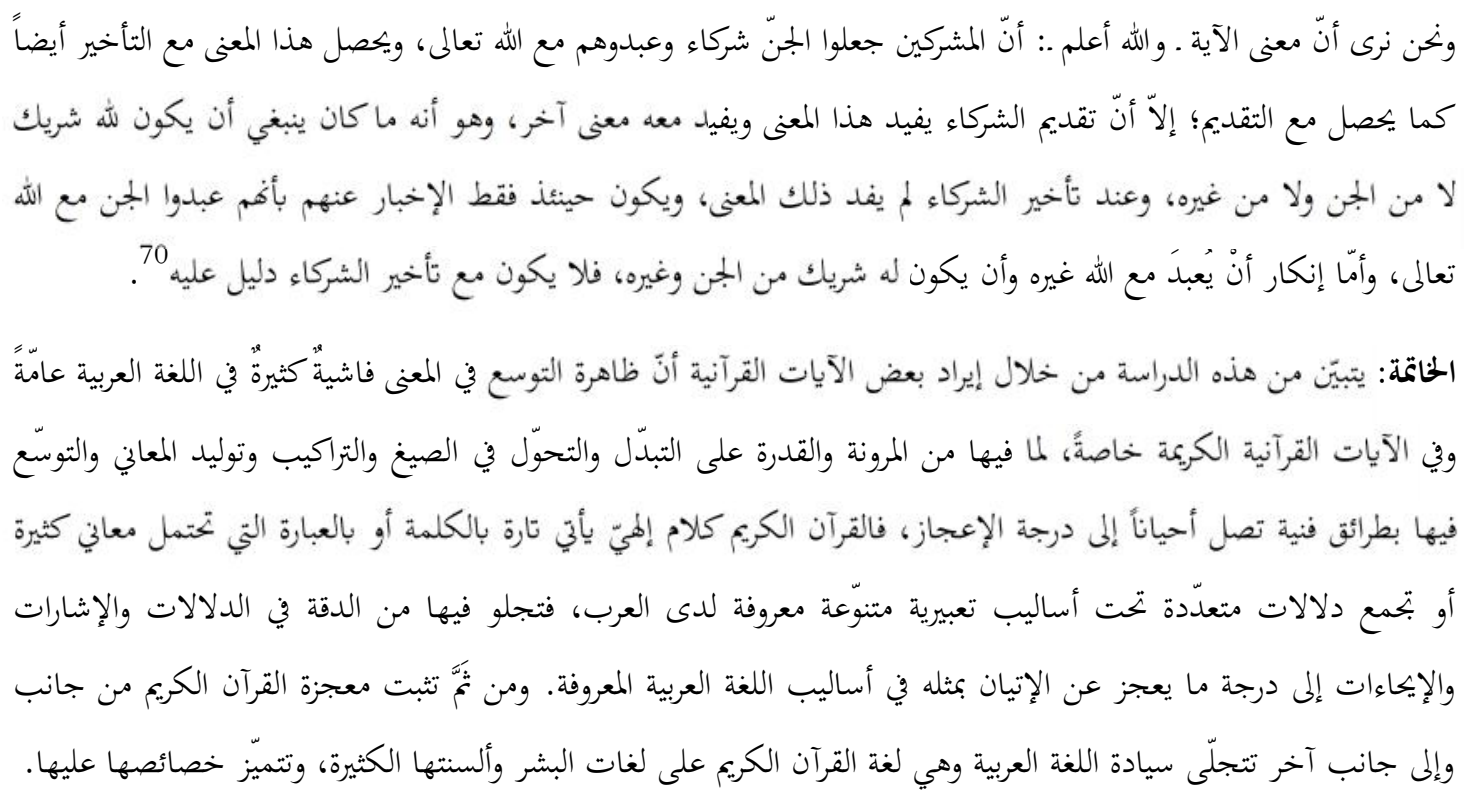

\section{Endnotes}

1. Ahmad Bin Faris, Mu'jam al Maqais al lugah, Tahqiq, 'Abdus Salam Harun (Dar Ihiya al Kutub al 'Arabiyah, 'Isa al Babi al Halabi, $1^{\text {st }}$ edition, 1366 H), Maddah, al waw, wal Sin wal 'Ayeen, Ibn Manjur, Lisan al Arab (Bairut: Dar al Fikr, Dar Sader, except date), 8/392- 393, Maddah [wasi'a].

2. Muhammad al Tunjee, Raji al Asmar, Al Mu'jam al Mufassal fi 'Ulumi al Lugah (Bairut: Dar al Kutub al 'Ilmiyah, $1^{\text {st }}$ edition, 1993), 1/213- 214.

3 . Ibid, 1/213- 214 .

4. Masir Abu Hamdan, Al iblagiyatu fi al Balagah al 'Arabiyah (Bairut: Mansurat 'Uaidat al Dualiyah, $1^{\text {st }}$ Print, 1991), Pp. 127-128.

5 . Ibid, p. 128.

6. This is for Suhaim 'Abd Bani al Hashas, Diwanuhu, Tahqiq, 'Abd al 'Aziz al Maymani (Qairo: Al Dar al Qawmiyah, copied from Dar al kutub, 1369 H), p. 16.

7. Ibn Zinni, Abul Fath uthman ibn zinni, Al Khasais, Tahqiq, Muhammad Ali al Najjar (Bairut: Dar al Kitab al 'Arabi, $2^{\text {nd }}$ edition, exp. date), 2/488, 489.

8. Al Jurjani, Abdul Qahir, Dalail al I'jaj, Tashih: Muhamma Abduhu and Muhammad Shankiti (Bairut: Dar al Ma'rifah, 1978), Pp. 221- 222. 


$$
\text { التوسّع في المعنى في اللغة العربية: دراسة تطبيقية لنماذج من آي القرآن الكري / الدكتور مُحَّمَ عبد الصمد }
$$

9. Abul Faraj al Asfahani, Al Agani, Tahqiq, Samir jabir (Bairut, Dar al Fiqr, $2^{\text {nd }}$ edition, except date), 15/77.

10 . Ibn Jinni, Al- Khasais 3/172-173.

11. Al Suyuti, Jalal uddin Al Muzhir fi 'ulum al Lugah wa anwa'uha, Sharh wa Tashih, Muhammad Ahmad Jad al Moula and others (Qairo, Dar al Turas, $2^{\text {nd }}$ edition, except date, 1/369, Tawfiq Muhammad Shaheen, Al Mushtaraq al lugawee Nadriyatan wa Tabiqan (Qairo, Matba'h al Da'wah al Islamiyah, Maktabah Wahbah, $1^{\text {st }}$ edition, 1980), p. 28.

12. Sibawaihi, 'Amru Bin 'uthmān Bin Qunbur, al-Kitāb, $3^{\text {rd }}$ edition, Taḥqīq: ‘Abd al-Salām Hārūn (Bairut: 'Alamul Kutub, $2^{\text {nd }}$ edition, 1983), 1/24.

13 . Al- Suyti, Al-Muzhir, 1/370, 374-375.

14 . Ibid, $1 / 371$.

15 . Ibid, $1 / 376$.

${ }^{16}$. Ibn Qutaibah, Tafsir Gareeb al Qur'an, Tahqiq, Al Sayed Ahmad Saqar (Bairut, Dar al Kutub al 'Ilmiyah, 1987), p. 221, Ibn Manjur, Lisan al Arab, 1/119, 120 [Fata], Taher bin 'Ashur, Al Tahrir wa al Tanweer (Teunisis, Al Dar al Teunisiya li al nasar, Al Muassasah al wataniyah li al Kitab, Al Jazair, 1984), 13/44.

17. Ibn Manjur, Lisan al Arab, 1/120, Taher Ahmad al Zawi, Tartib al Qamus al Muhit (Bairut: Darul Ma'rifah, Madda: [Fataa].

18 . Dr. Fadil Saleh al Samurai, Al Jumlah al Arabiyah wal Mana (Bairut: Daru Ibn Hazam, $1^{\text {st }}$ edition, 2000), p. 168.

19. Al Zamakhshari, Jar Allah, Al Kasshaf (Bairut, Dar al Ma'rifah li al Tiba'ah wa al Nashar, expt date), 3/176, Abu Hayaan al Andalusi, Al Bahr al Muhit, Tahqiq, 'Aadel Ahmad 'Abdul Mawjud and Others (Bairut, Dar al Kutub al 'Ilmiyah, $1^{\text {st }}$ edition, 1993), 8/184.

20. Al Zajjaj, I'rab al Qur'an, Tahqiq, Ibrahim al Abyaree (Iran, Qum, Muassasah Matbu'ati Isma' eelian, $2^{\text {nd }}$ edition, 1982), 2/763.

21. Al Qalaqshandi, Ahmad bin 'Ali, Sub al A'sha fi sana'a al Insha, Tahqiq, Dr. Yusuf 'Ali Taweel (Dimausc, Dar al Fikr, $1^{\text {st }}$ edition, 1987), 2/213.

22. Ibn Qutaibah, Tafsir Gareeb al Qur'an, p. 435.

23 . Ibn Faris, Maqayeesul lugah, Chapter: Al Nun, Al Ha.

24 . Ibn Manzur, Lisanul Arab, 5/236, Madda [Nahra]. 
25

Dr. Samurai, Al Jumlah al Arabiyah wal Mana, p. 168.

26 . Sibawaihi, al-Kitāb 4/37-38, Ibn Sydah, Al Mukhassas, Tahqiq, Lajnatu Ihiya al Turath al 'Arabi (Bairut, Mansurat Dar al Aafaq al Jadidah, except date) 16/155-161.

27 . Dr. Samurai, Al Jumlah al Arabiyah wal Mana, p. 170.

28. Al Baihaqi, Ahmad bin Husain, Al Sunan al Kubra (Haidarabad, India, Majlis Daira al Ma'arif al Nizamiyah, $1^{\text {st }}$ edition, 1344 H.), 2/210, Muhammad Nasir Uddin Al Bani, Irwa al Galil, Ishraf, Muhammad Zuhair al Shaweesh (Bairut, Al Maktab al Islami, $2^{\text {nd }}$ edition, 1985), 2/170.

29 Ibn Faris, Maqayeesul lugah, Chater, Al Ha wal Fa.

30. Al Tabari, Muhammad Bin Jarir, Tafsir al Tabari (Bairut, Dar al Kutub al 'Ilmiyah, $2^{\text {nd }}$ edition, 1997), 7/620.

31. Al Zamakhsari, Alkasshaf, 4/191.

32. Abu Haiyan al Nahwi, Al Bahrul Muhit 8/377.

33 .Dr. Fadil Samurai, Al Jumlah al Arabiyah wal Mana, p. 171.

34 .Ibid, p. 402, Ibn Faris, Maqayeesul lugah, Chater, Al Ra wal Ha, Ibn al Anbari, Al Addad, Tahqiq, Muhammad Abu al Fadal Ibrahim (Bairut, Al Maktabah al 'Asriyah, Sayda, 1987), p. 151, Tawfiq Muhamma Shaheen, Al Mushtarak al lugawee Nazryiatan wa Tatbiqan (Qairo, Matba'a al Dawa al Islamiyah Maktaba Wahba, $1^{\text {st }}$ edition, 1980), Pp. 283-284.

35. Abul Baqa al 'Ukburi, 'Abdullah bin al Hussain, Al Tibyan fi I'rab al Qur'an, Tahqiq, 'Ali Muhammad al Bajawee ('Isa al Babi al Halabi wa Shurakahu, except date), 1/194, Abu Haiyan al Nahwi, Al Bahrul Muhit 2/261.

36. Al Farra, Abu Zakaria Yiayia bin Ziad, Ma'ani al Qur'an (Bairut, 'Alam al Kutub, 2 ${ }^{\text {nd }}$ edition, 1983), 1/187.

37. Abu Haiyan al Nahwi, Al Bahrul Muhit 2/370, Al Samin al Halabi, Ahmad bin Yusuf, Al Dur al Masun fi 'Ulum al Kitab al Maknun, Tahqiq, Dr. Ahmad Muhammad al Khrrat (Dimusq, Dar al Qalam, $1^{\text {st }}$ edition, 1986), 2/675.

38. Abu Haiyan al Nahwi, Al Bahrul Muhit 2/370, Al Zarkashi, Badr al Deen Muhammad bin 'Abdullah, Al Burhan fi 'Ulum al Qur'an, Tahqiq, Muhammad Abu al Fadal Ibrahim (Bairut, Dar al Jeel, 1988), 2/207.

39 Dr. Samurai, Al Jumlah al Arabiyah wal Mana, p. 175.

40.Al Farra, Ma'anil Qur'an 1/273, wa Ibn Qutaibah, Garibul Qur'an, p. 129. 


$$
\text { التوسّع في المعنى في اللغة العربية: دراسة تطبيقية لنماذج من آي القرآن الكري / الدكتور مُحَّمَ عبد الصمد }
$$

41 . Dr. Samurai, Al jumlah al Arabiyah wal Mana, p. 177, Mahmud Safi, Al Jawal fi I'rab al Qur'an wa Sarfihi wa Bayanihi (Dimusq, Dar al Rashid, $2^{\text {nd }}$ edition, 1995) 5/58, Al Bahrul Muhit 3/282.

42 Abu Haiyan al Nahwi, Al Bahrul Muhit 4/313, Ibn 'Ashur, Al Tahrir wal Tanwir 8/175, Al Jumlah al Arabiyah wal Mana, Pp. 178-179.

43. Ibn 'Ashur, Al Tahrir wal Tanwir, 8/176.

44. Al Ragib al Asfahani, Abul Qasim, Al Mufradat fi Garib al Qur'an, Tahqiq, Muhammad Sayed Kilani (Bairut, Dar al Ma'rifa, except date), p. 271, Kitab as Shin.

45. Al Imam al Bukhari, Abu 'Abdullah Muhammad bin Isma'il, Sahih al Bukhari, Tahqiq, Muhammad zuhair bin Nasir al Nasir (Dar Tawaq al Najat, $1^{\text {st }}$ edition, 1422 H.), 4/29, Kitab al Jihad al Siar.

46 . Dr. Samurai, Al jumlah al Arabiyah wal Mana, p. 177.

47. Such as: Thakhfif, Iejaz, Ikhtisar fil kalam, Tafkhim, etc.

48 . Taher Sulaiman Hamudah, Zahira al Hazf fi al Dars al lugwee (Al Iskandariyah, al Dar al Jmi'yah li al Tiba'h wa al Nashar wa al Tawzee', except date), Pp. 97, 180-181.

49. I'rabul Quraan al Manub ila Al Zajjaj 1/125, Al Samin al Halabi, Al Durrul Masun 4/106.

50. Sahihul Bukhari, 7/18, No 5140.

51. Al Zamakhsari, Alkasshaf, 2/80, 81, Al Bahrul Muhit 4/302, 303, Hasan Tabal, Uslub al Iltifat fi al Balagah al Quraniyah (Qairo, Dar al Kutub, 1990), Pp. 190-191.

52. Ibn Manzur, Lisanul Arab, 10/371, Madda, [Wasaka], Abu Haiyan al Nahwi, Al Bahrul Muhit 4/415, Al jumlah al Arabiyah wal Mana, p. 183.

53. Al Zamakhsari, Alkasshaf 2/128, Al Bahrul Muhit 4/415, Al Durrul Masun 5/505, Al jumlah al Arabiyah wal Mana, p. 183.183

54. Ibn Manzur, Lisanul Arab, 13/257, Maddah [Damn].

55. 'Abdul Fattah Hasan Ali al bajjah, Zahirtu Qias al Jumal fi al lugati a 'Arabiyah baina 'ulamai al lugah al Qudama wal Muhdasin (Jordan, Amman, Dar al fikr, $1^{\text {st }}$ edition, 1998), p. 253.

56 . Ibn Jinni, Al Khasais, Ibn Hisam, Mugni al labib 'an kutub al aa'rib, Tahqiq, Mazin al Mubarak and others (Bairut, Darul Fikir, $2^{\text {nd }}$ edition, 1972), p. 897.

57. Al 'Abbas Hasan, Al Nahw al Wafi (Qairo, Dar al Ma'arif, $7^{\text {th }}$ edition, except date), 2/169- 170. 
58. Al Kafawee, Abul Baqa, Al Kulliyat (Bairut, Muassasatu al Risalah, 2 ${ }^{\text {nd }}$ edition, 1993), p. 266.

59 . Khalid al Azhary, Sharh al Tasrih 'Ala al Tawdih, Hasitu Yasin (Dar al Ihiya al Kutub al 'Arabiyah, 'Isha al Babi al Halabi wa Shurakahu, Egypt), 2/4, 5.

60. Ibn 'Usfur, Daraeru al Shi'ri, Tahqiq, Al Sayed Ibrahim Muhammad (Barut, Dar al Andalus, $2^{\text {nd }}$ edition, 1982), p. 239.

61. Abu Haiyan al Nahwi, Al Bahrul Muhit 4/356, Al Zarkashi, Al Burhan fi 'Ulum al Qur'an, 3/338.

62. Al Zamakhsari, Alkasshaf, 2/481.

63 . Ibn al Sajari, Hibatullah bin 'Ali, bin Hamzah al 'Alawee, Amali ibn al Sajari, Tahqiq, Dr. Mahmud Al Tanahi (Qairo, Al Nasir, Maktabatul Khanzi, except date), 1/223, Al Zarkashi, Al Burhan fi 'Ulum al Qur'an, 3/340.

64 . Ibid, $3 / 233$.

65. Samir Ahmad Ma'luf, Hayweat al lugati al 'Arabiyati Baina al Haqiqati wal Majaz (Dimusq, Mansurat Ittihad al Kitab al ‘Arabi, 1996), p. 305.

66 .Sibawaihi, al-Kitāb, 1/34.

67. Al Alusi, Shihab Uddin Mahmud, Ruh al Ma'ani fi Tafsir al Qur'an al 'Azim wal Sab'i al Mathani (Bairut: Dar al Ihiya al Turath al 'Arabi, except date) 24/68, Dr. Samurai, Al jumlah al Arabiyah wal Mana, p. 190.

68 . Ibid, p. 190.

69 . Abu Haiyan al Nahwi, Al Bahrul Muhit 4/196, 197.

70. Abdul Qahir al Jurjani, Dalail al 'Ijaz, Tashih, Mohammad 'Abduhu and Mohammad al Shaqiti (Bairut: Dar al Ma'rifah, 1978), Pp. 221-223. 